American Journal of Applied Sciences 5 (8): 1029-1033, 2008

ISSN 1546-9239

(C) 2008 Science Publications

\title{
Power Quality Improvement Using a Sliding Mode Control of a Series Active Filter
}

\author{
Theerayuth Chatchanayuenyong \\ Faculty of Engineering, Mahasarakham University, \\ T. Khamriang, A.Kantarawichai, Mahasarakham, 44150, Thailand
}

\begin{abstract}
A sliding mode controller (SMC) for a three-phase series active filter was proposed to compensate voltage unbalances, suppress voltage sags and swells and hence improve the power quality of a three-phase ac system. The voltage unbalance compensation and regulation is only based on the positive sequence component decomposition of the supply voltage that is then adjusted to a rated value and used as the reference voltage for the sliding mode controller. This study also includes compensation algorithm, design equations and circuit design criteria. Simulation results ensure the concept and validity of the proposed control system.
\end{abstract}

Key words: Sliding mode control, series active filter, power quality improvement, voltage unbalance, voltage sags, voltage swells

\section{INTRODUCTION}

The power quality in distribution system, especially voltage quality is very important for both industrialized and developing countries. Computers and sensitive electronic equipment are used in everywhere nowadays. A poor power quality can damage or degrade these equipments. In industry and commercial plant and insufficient power quality can lead to the poor quality of products, interruption of important industrial processes and hence economic losses. The factors that affect the voltage quality are voltage unbalance, voltage sags and swells. Voltage unbalance can occur due to an incomplete transposition of transmission lines, unbalanced loads, open delta transformer connection, disconnected three-phase capacitor bank and the proliferation of nonlinear and large single-phase loads ${ }^{[1]}$. Voltage unbalance worsens the operation of $\mathrm{AC}$ electric machines. The negative sequence component in voltage unbalance causes large transient current that leads to reduction of the net torque, increase in losses and temperature rise ${ }^{[2]}$. Voltage sags and partial or total collapses of one or more phases are normally caused by faults on adjacent feeders such as phase to ground or phase to phase faults. Voltage swells are caused by power factor correction capacitors and transformer switching. Voltage sags or collapse and voltage swells can temporarily interrupt the operation of electrical machine and equipment.

A number of topologies and algorithm to improve the voltage quality have been presented in the literature. However, most of the proposed controllers are open loop based on three-symmetrical component; zero sequence, negative sequence and positive sequence, decomposition to balance and regulate the voltage. Among these papers are a series active filter power filter which compensates voltage unbalance presented by Moran et $\mathrm{al}^{[3]}$, an active line conditioner to balance voltage in a three-phase system presented by Bhavaraju and Enjeti ${ }^{[4]}$, distribution system voltage regulation under fault condition using static series regulator presented by Haddad and Joos ${ }^{[5]}$, etc..

This paper proposes a compensation algorithm using a series active filter associated with the sliding mode controller to compensate voltage unbalance and suppress voltage sags and swells. The proposed control structure is shown in Fig. 1.

It is based on a three-phase PWM voltage source inverter connected in series with the power lines through three single-phase current transformers. Three

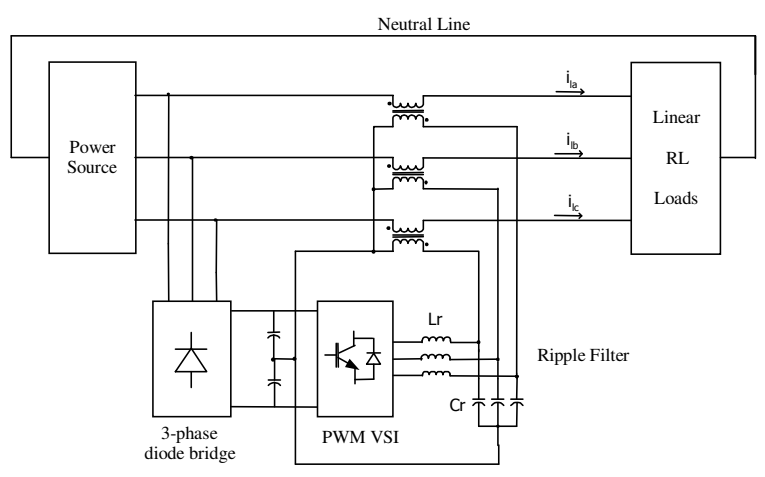

Fig. 1: Control structure of the proposed series active filter 
SMCs are employed to track the actual load voltage to the reference voltage. Only the positive sequence component is decomposed from the supply voltage, which is then adjusted to a rated value and used as a reference voltage for the sliding mode controllers. No zero and negative sequence component decompositions are needed in the algorithm; hence, the computational time of the controller is reduced. This leads to the faster response to the transient state of the fault. Furthermore, the proposed algorithm employs a closed loop control system, so the control accuracy and response is much better than the conventional open loop control system.

In the following sections, voltage compensation algorithm, power circuit and simulation results are presented respectively.

\section{VOLTAGE COMPENSATION ALGORITHM}

The principle of a voltage compensation is based on the extracting of the positive sequence component from three-phase supply voltages using a transformation given in Eq. 1.

$$
\mathrm{v}_{\mathrm{a} 1}=\frac{1}{\sqrt{3}}\left[\mathrm{v}_{\mathrm{a}}+\alpha \mathrm{v}_{\mathrm{b}}+\alpha^{2} \mathrm{v}_{\mathrm{c}}\right]
$$

where $v_{a}, v_{b}$ and $v_{c}$ represent the phase to neutral source voltages.

$\mathrm{v}_{\mathrm{a} 0}, \mathrm{v}_{\mathrm{a} 1}$ and $\mathrm{v}_{\mathrm{a} 2}$ represent the zero, positive and negative sequence voltage components of phase-a voltage respectively.

$\alpha=\mathrm{e}^{\mathrm{j} 2 \pi / 3}$ is a phase-shift operator.

It should be noted that the positive sequence of phase- $b$ and phase-c voltages can be calculated from equation similar to Eq. 1. However the results will be merely $120^{\circ} \mathrm{C}$ phase-shifted from the corresponding components of phase-a voltage. Thus the calculation for the two remaining phases would be unnecessary.

These positive sequence components shall be used to generate reference voltage for the sliding mode controller.

\section{REFERENCE VOLTAGE GENERATION}

Let $\mathrm{v}_{1}(\mathrm{t})$ represents an instantaneous positivesequence voltage with amplitude $\mathrm{V}_{1}$ and phase angle $\varphi$ defined by

$$
v_{1}(t)=V_{1} \sin (\omega t+\varphi)
$$

The amplitude $\mathrm{V}_{1}$ are calculated from data in a short time window using two samples of the signal $\mathrm{v}_{1}(\mathrm{t})$ as shown below ${ }^{[6]}$.

$$
\mathrm{v} 1=\frac{\left[v_{1(\mathrm{k}+1)}^{2}+v_{1(\mathrm{k})}^{2}-2 v_{1(\mathrm{k}+1)} v_{1(\mathrm{k})} \cos \left(\omega \mathrm{T}_{\mathrm{s}}\right)\right]^{0.5}}{\sin \left(\omega \mathrm{T}_{\mathrm{s}}\right)}
$$

where $v_{1(\mathrm{k}+1)}$ and $v_{1(\mathrm{k})}$ represent the positive sequence voltage component at instant $\mathrm{t}_{(\mathrm{k}+1)}$ and $\mathrm{t}_{(\mathrm{k})}$ respectively, $\mathrm{T}_{\mathrm{s}}$ is a sampling period equal to $\mathrm{t}_{(\mathrm{k}+1)}-\mathrm{t}_{(\mathrm{k})}$.

The reference voltage for the sliding mode controller are calculated as shown in Eq. 4 and 5.

$$
\begin{gathered}
v_{\text {rated }}(t)=\frac{V_{\text {rated }}}{V_{1}} \times v_{1}(t) \\
{\left[\begin{array}{l}
v_{\text {refa }} \\
v_{\text {refb }} \\
v_{\text {refc }}
\end{array}\right]=\frac{1}{\sqrt{3}}\left[\begin{array}{ccc}
1 & 1 & 1 \\
1 & \alpha^{2} & \alpha \\
1 & \alpha & \alpha^{2}
\end{array}\right]\left[\begin{array}{l}
0 \\
v_{\text {rated }} \\
0
\end{array}\right]}
\end{gathered}
$$

where:

$v_{\text {rated }}=$ Rated voltage

$v_{\text {rated }}=$ Rated amplitude of load voltage.

\section{SLIDING MODE CONTROLLER} by

A variable structure control law of SMC is given

$$
u(t)=-\rho \operatorname{sgn}(s(t))
$$

or

$$
u(t)=\left\{\begin{array}{r}
-\rho \text { if } s(x, x, t)>0 \\
\rho \text { if } s(x, x, t)<0
\end{array}\right.
$$

where:

$\rho \quad=$ Sliding gain

$\operatorname{sgn}(\cdot)=$ Signum or the sign function

The switching function $s(t)$ is defined by

$$
\mathrm{s}(\mathrm{x}, \mathrm{x}, \mathrm{t})=\mathrm{e}
$$

where:

$\mathrm{e}=$ Tracking error in the variable $=$ load phase voltage$\mathrm{V}_{\text {ref }}$

The Sliding mode controller block diagram is shown in Fig. 2.

\section{GATING SIGNAL GENERATION}

The gating signals of the inverter are generated by comparing the control command, $\mathrm{u}(\mathrm{t})$ in Eq. 7 with a triangular waveform whose frequency is kept constant at $6 \mathrm{kHz}$ as shown in Fig. 3 . 


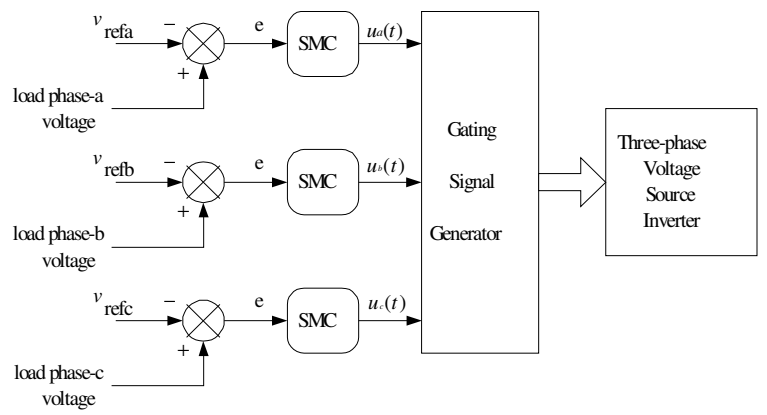

Fig. 2: Sliding mode controller block diagram

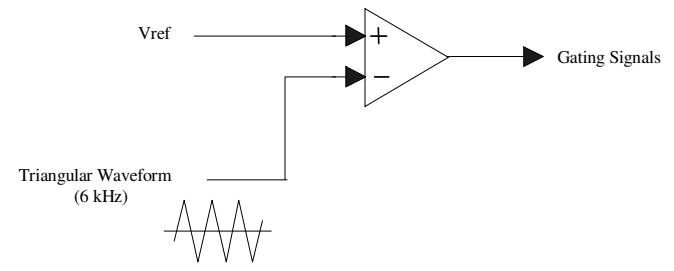

Fig. 3: Sliding mode controller block diagram

\section{POWER CIRCUIT DESIGN}

In order to quantify the degree of unbalance in the voltages, an unbalance factor must be defined. The unbalance factor, UF is the ratio between the sum of zero sequence and negative sequence voltages $v_{0}+v_{2}$ and the positive sequence voltage $\mathrm{v}_{1}$.

$$
\mathrm{UF}=\frac{v_{0}+v_{2}}{v_{1}}
$$

Similarly, the error between the load voltage and the required rated voltage can be quantified using a magnitude factor. The magnitude factor, MF, is the ratio between the positive sequence voltage and a rated line to line voltage required by loads $\mathrm{v}_{\text {rated }}$.

$$
\mathrm{MF}=\frac{v_{1}}{v_{\text {rated }}}
$$

\section{CURRENT TRANSFORMER (CT)}

The purpose of the CT's is not only to isolate the PWM inverter from the power system, but also to match the voltage and current ratings of the PWM inverter with that of the power system.

The maximum secondary voltage of the $\mathrm{CT}$ is given by

$$
\mathrm{V}_{\mathrm{s}, \max }=\frac{\left(\mathrm{V}_{\text {rated }}-\mathrm{V}_{1}\right)+\left(\mathrm{V}_{0}+\mathrm{V}_{2}\right)}{\sqrt{3}}
$$

which can be written in term of MF and UF as shown below.

$$
\mathrm{v}_{\mathrm{s}, \max }=\frac{\left\lfloor 1-|\mathrm{MF}|_{\text {min }}\left(1-|\mathrm{UF}|_{\text {max }}\right)\right\rfloor \cdot \mathrm{V}_{\text {rated }}}{\sqrt{3}}
$$
by

The maximum primary voltage of the $\mathrm{CT}$ is given

$$
\mathrm{V}_{\mathrm{p}, \max }=\mathrm{G} \cdot \mathrm{V}_{\mathrm{dc}}
$$

where $\mathrm{G}$ is the inverter gain.

The total apparent power rating (VA rating) of each $\mathrm{CT}$, which is $1 / 3$ of the inverter's rating, is given by

$$
\mathrm{S}_{\max }(\operatorname{each} \mathrm{CT})=\mathrm{V}_{\mathrm{s}, \text { max }} \cdot \mathrm{I}_{\text {rated }}
$$

where $\mathrm{I}_{\text {rated }}$ is rated load current.

The turn ratio, a, of the current transformer is selected in accordance with the inverter dc bus voltage, $\mathrm{V}_{\mathrm{dc}}$ and load rated voltage, $\mathrm{V}_{\text {rated }}$ as follows.

$$
\text { CT turn ratio(a) }=\frac{\mathrm{n}_{2}}{\mathrm{n}_{1}}=\frac{\mathrm{V}_{\mathrm{dc}} / 2}{\mathrm{~V}_{\text {rated }} / \sqrt{3}}
$$

\section{PWM VOLTAGE-SOURCE INVERTER}

The rated apparent power required by the inverter can be obtained by computing the apparent power generated in the primaries of the current transformers as illustrated below.

$$
\mathrm{S}_{\max }(\text { inverter })=3 \cdot \mathrm{V}_{\mathrm{s}, \text { max }} \cdot \mathrm{I}_{\text {rated }}
$$

The inverter switch ratings are defined by the following equations.

$$
\begin{gathered}
\mathrm{V}_{\mathrm{swpk}}=\mathrm{V}_{\mathrm{dc}} / 2 \\
\mathrm{I}_{\mathrm{swpk}}=\sqrt{2} \cdot \frac{\mathrm{V}_{\mathrm{s}, \max } \cdot \mathrm{I}_{\text {rated }}}{\mathrm{V}_{\mathrm{p}, \max }}
\end{gathered}
$$

\section{PASSIVE FILTER TO SUPPRESS SWITCHING RIPPLES}

As shown in Fig. 1, the purpose of $\mathrm{Lr}$ and $\mathrm{Cr}$ connected in the primary of the CT is to suppress the switching voltage ripples caused by the voltage source PWM inverter. 


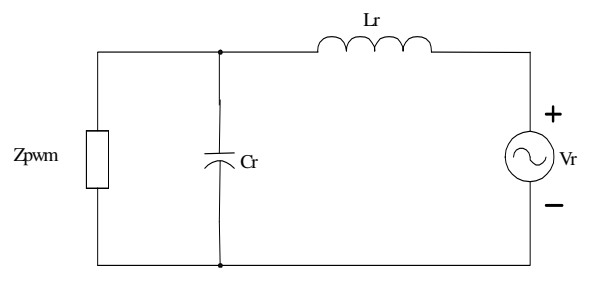

Fig. 4: Equivalent circuit for $\mathrm{Vr}$

Fig. 4 shows the equivalent circuit for the switching voltage ripple Vr.

Zpwm is the amplitude of Zs (source impedance), which is seen from the primary of the CT and can be represented as

$$
\mathrm{Z}_{\mathrm{pwm}}=\left(\frac{\mathrm{n}_{1}}{\mathrm{n}_{2}}\right)^{2}\left|\mathrm{Z}_{\mathrm{s}}\right|
$$

At the frequency of the triangular waveform, the following relation between the ripple filter parameters has to be satisfied.

$$
X_{\mathrm{crf}}=\left\langle\left\langleX _ { \mathrm { lrf } } \left\langle\left\langle Z_{\mathrm{pwm}}\right.\right.\right.\right.
$$

where $X_{\text {crf }}$ and $X_{\text {lrf }}$ are the capacitive and inductive reactance of the ripple filter respectively.

The design criteria for $X_{\text {crf }}$ and $X_{\text {lrf }}$ is such that the voltage drop in the inductor at the ripple frequency must be larger than the voltage drop in the capacitor, however for the frequency that needs to be compensated, the voltage drop in the capacitor must be larger than the voltage drop in the inductor ${ }^{[6]}$.

\section{SIMULATION RESULTS}

The proposed series active filter has been verified by simulation. The results are divided into 5 categories according to the arbitrary imposed supply conditions, as shown in Fig. 5-9. In each case, the compensator begins to operate at $40 \mathrm{~ms}$.

Case 1: Balance voltage sags with $|\mathrm{MF}|=0.65$

Case 2: Balance voltage swells with $|\mathrm{MF}|=1.35$

Case 3: Unbalance voltage sags with $|\mathrm{UF}|=0.261$ and $|\mathrm{MF}|=0.516$

Case 4: Unbalance voltage swells with $|\mathrm{UF}|=0.144$ and $|\mathrm{MF}|=1.20$

Case 5: 1 -phase loss with $|\mathrm{UF}|=0.552$ and $|\mathrm{MF}|=$ 0.766

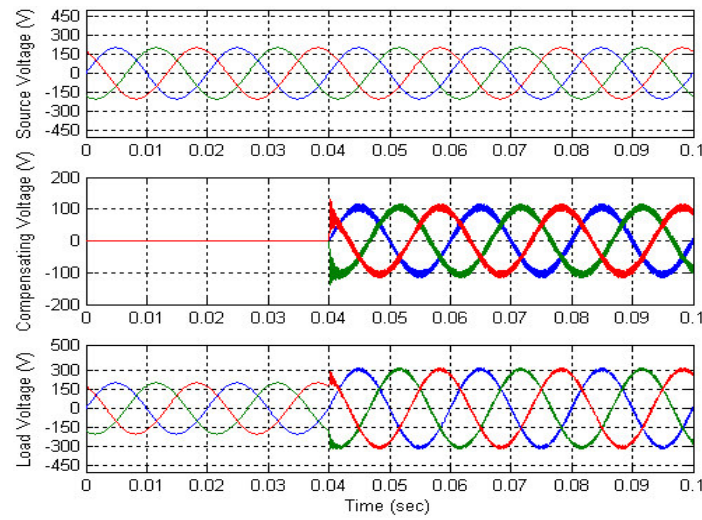

Fig. 5: Case 1: Load phase voltage, compensating voltage and source phase voltage in case of balance voltage sags with $|\mathrm{MF}|=0.65$

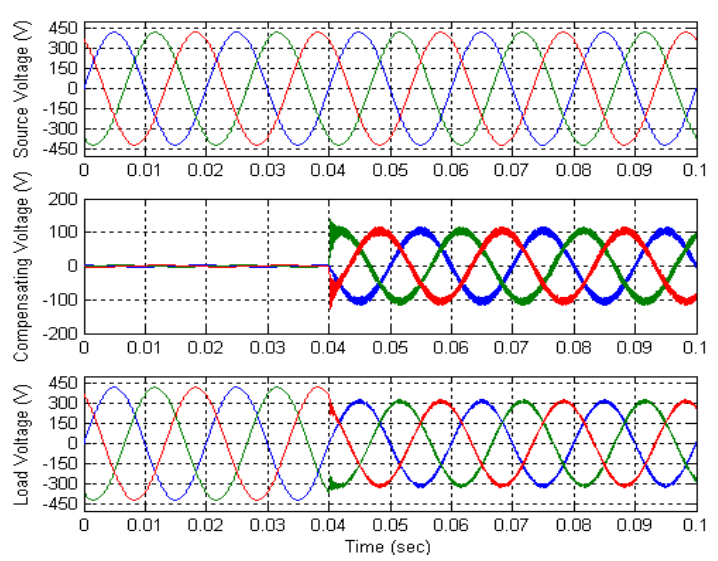

Fig. 6: Case 2: Load phase voltage, compensating voltage and source phase voltage in case of balance voltage swells with $|\mathrm{MF}|=1.35$

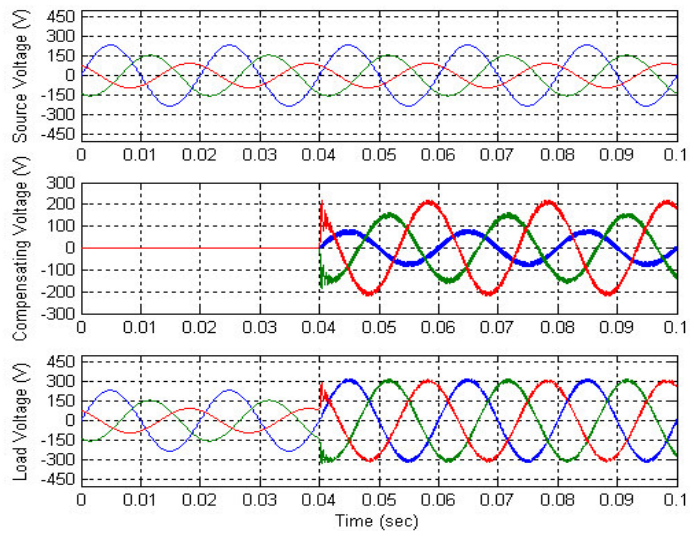

Fig. 7: Case3: Load phase voltage, compensating voltage and source phase voltage in case of 


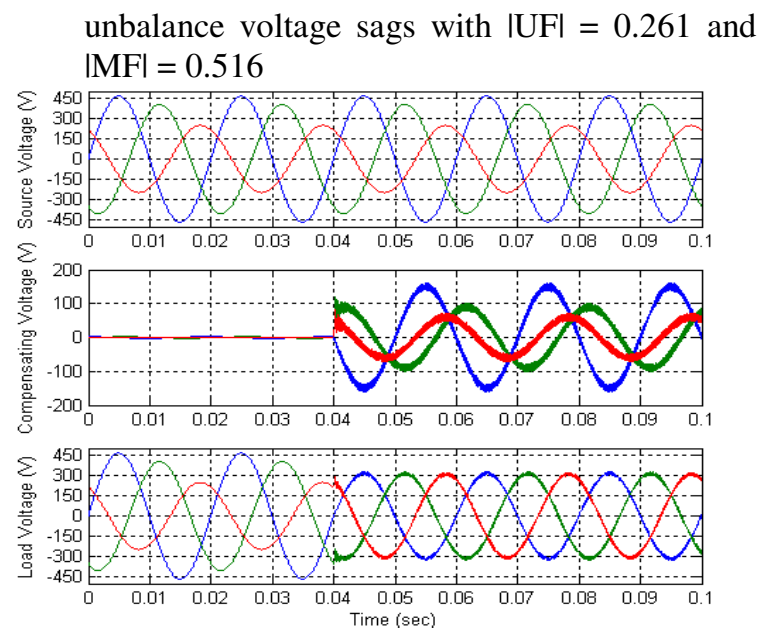

Fig. 8: Case 4: Load phase voltage, compensating voltage and source phase voltage in case of unbalance voltage swells with $|\mathrm{UF}|=$ 0.144 and $|\mathrm{MF}|=1.20$

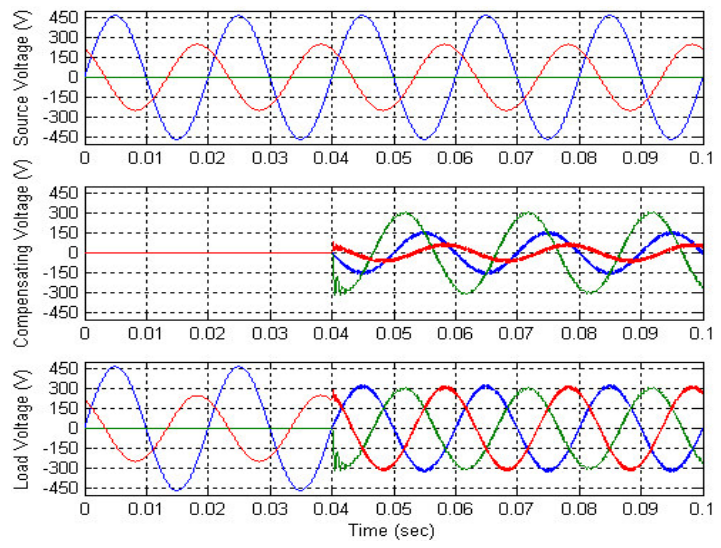

Fig. 9: Case 5: Load phase voltage, compensating voltage and source phase voltage in case of 1phase loss with $|\mathrm{UF}|=0.552$ and $|\mathrm{MF}|=0.766$

\section{CONCLUSION}

This study has shown the feasibility and compensation capability of a three-phase series active filter (SAF) with sliding mode controller. The SAF based on a three-phase voltage source inverter connected in series to the supply through transformers. The SMC, of which the control structure is simple and easily to apply was employed to track the load voltage to the reference voltage. Its performance is very good in term of the control accuracy and response. The proposed SAF can compensate voltage unbalance, sags and swells and hence improve the power quality of the electrical distribution system. Voltage balancing and regulation was successfully done without zero and negative sequence component decomposition. This reduces the computational time of the controller and leads to a fast response to the system transience. The simulation results show a very good performance of the proposed SAF configuration and control scheme.

\section{ACKNOWLEDGEMENT}

This research is financially supported by Faculty of Engineering, Mahasarakham University.

\section{REFERENCES}

1. Lee, C.Y., B.K. Chen, W.J. Lee and Y.F. Hsu, 1997. Effects of various unbalanced voltages on the operation performance of an induction motor under the same voltage unbalance factor condition: Annual meeting, IEEE, pp: 51-59.

2. Souto, O.C.N., J.C. de Oliveira, P.F. Ribeiro and L.M. Neto, 1998. Power quality impact on performance and associated costs of three-phase induction motors: Proc. Harmonics and Quality of Power, 2: 791-797.

3. Moran, L., P. Werlinger, J. Dixon and R. Wallace, 1995. A series active power filter which compensates current harmonics and voltage unbalance simultaneously: Proc. IEEE PESC 95, pp: 222-227.

4. Bhavaraju, V.B. and P.N. Enjeti, 1996. An active line conditioner to balance voltages in a threephase system: IEEE Trans. Ind. Applicat., 32: 287292.

5. Kevork Haddad and Geza Joos, 1997. Distribution System Voltage Regulation under Fault Conditions using Static Series Regulators, IEEE Industry Applications Society Annual Meeting, New Orlean, pp: 5-9.

6. Kevork Haddad and Geza Joos, 1998. A Fast Algorithm for Voltage Unbalance Compensation and Regulation in Faulted Distribution Systems: IEEE-APEC Annual Meeting, pp: 963-969. 